\title{
ROLE OF SONOELASTOGRAPHY IN THE EVALUATION OF THYROID NODULES
}

\author{
Mujaddad Ahmad ${ }^{1}$, Mubeen Shoukat ${ }^{1}$, Asad Ullah $^{1}$, Tayyaba Aslam ${ }^{1}$, Waris Ali ${ }^{1}$, Aleena Khalil ${ }^{1}$, Muhammad \\ Hammad Durrani ${ }^{1}$, Muhammad Hamza ${ }^{1}$, Syed Zia ul Hasnain ${ }^{1}$, Bisma Akhtar ${ }^{1}$, Dr. Sajid Shaheen Malik ${ }^{2} \&$ \\ Dr. Zeeshan Rashid Mirza ${ }^{3}$. \\ ${ }^{1}$ Medical Imaging Doctor, University Instituste of Radiological Sciences and Medical Imaging Technology, \\ University of Lahore, Lahore-Pakistan \\ ${ }^{2}$ University Institute of Radiological Sciences and Medical Imaging Technology, University of Lahore, Lahore- \\ Pakistan \\ ${ }^{3}$ Department of Radiology, Institute of Nuclear Medicine and Oncology Lahore (INMOL) Pakistan. \\ Correspondence: Mujaddad Ahmad, 283-D Audit \& Account Housing Society Phase 1 near Valencia Town \\ Lahore, Lahore-Pakistan. Mobile:+923457006859 E-mail: mujadadgondal@gmail.com
}

\begin{abstract}
Thyroid nodular disease is one of the most common endocrine disorder. B mode ultrasound provides useful characteristic information about thyroid nodules but it has noticeably low accuracy to differentiate benign from malignant. Fine needle aspiration is widely been used in differentiation of benign and malignant thyroid nodules but it is an invasive procedure. Sonoelastography is a newly developed non- invasive technique which uses ultrasound and gives information about the stiffness of tissue. It estimates the hardness of thyroid lesions in association with adjacent tissues and assists in the differentiation of benign from malignant nodules.Objective: The objective of this study was to evaluate the role sonoelastography in the evaluation of thyroid nodules. Methods: This study was conducted on 72 Patients of age between 18-80 years of either gender at Institute of Nuclear Medicine and Oncology Lahore (INMOL) Pakistan, from 25 March 2019 to 23 August 2019 for duration of five months. Elastography was performed using Toshiba Aplio 500. Patient having one or more solid nodules in thyroid on conventional ultrasound examination were included in the study and the sonoelastography of nodules was confirmed with histopathological findings of nodules. Results: A total 72 participants were included in our study. The mean age of participants was 42.11 years. Gender distribution shows that $51.4 \%(\mathrm{n}=37)$ were male and $48.6 \%$ $(\mathrm{n}=35)$ were female. Sonoelastographic strain ratio of $55.6 \%$ nodules $(\mathrm{n}=40)$ was more than 2.1 (malignant feature) and $44.4 \%$ nodules $(n=32)$ have less than 2.1 (benign). Histopathology showed $56.9 \%$ of participants $(n=41)$ have malignant nodules and $43.1 \%(n=31)$ have benign nodules. The comparison of sonoelastography and histopathology in reference with nodules shows that the results of histopathology and sonoelastography were same and support each other. Conclusion: Sonoelastography is non-invasive and cost-effective imaging technique to diagnose thyroid nodules either benign or malignant.
\end{abstract}

Keywords: Ultrasound Elastography, Thyroid Nodules, Benign, Malignant, Fine Needle Aspiration.

DOI: $10.7176 / \mathrm{JHMN} / 66-08$

Publication date:September $30^{\text {th }} 2019$

\section{$1 \quad$ Introduction}

Thyroid nodular disease (TND) is one of the most common endocrine disorder. About 3 to 7 \%of the population have palpable nodules. Lesions in the ultrasonographic examination are reported in large part of the population which is more common in women and aged patients suffering from specific conditions like acromegaly ${ }^{1}$. According to the American Thyroid Association guideline, epidemiologic studies have demonstrated the prevalence of palpable thyroid nodules which are about $5 \%$ in women and $1 \%$ in men that are living in iodine sufficient parts of world ${ }^{2}$. Thyroid disease in Pakistan is one of the significant public health problems due to iodine deficiency and about $70 \%$ population of Pakistan is at risk of developing thyroid disease ${ }^{3}$.

The thyroid gland is commonly described as the largest endocrine gland which is consist of two lateral lobes (left and right) attached across the median line by isthmus ${ }^{4}$. Majority of patients with thyroid nodules usually have no symptoms. The thyroid nodules are generally diagnosed as an incidental finding on diagnostic imaging e.g. (Ultrasound, Magnetic Resonance Imaging, Computed Tomography, Positron Emission Tomography) which are performed for other indications ${ }^{5}$. Usually, the thyroid nodules grow inside the thyroid gland. Most of them are 
benign and only 4 to $6.5 \%$ are malignant ${ }^{6}$. According to recent studies the incidence of thyroid carcinoma has increased from $3.6 \%$ in 1973 to $9 \%$ in $2010^{7}$.In Pakistan thyroid carcinoma is a most typical endocrine malignancy and is about $1 \%$ of all cancers with papillary carcinoma being the most common of thyroid malignancies $(69-71 \%)$ followed by follicular carcinoma $(11.6-13 \%)^{8-9}$.

B mode ultrasound provides useful characteristic information about thyroid nodules such as size, borders, Echogenicity and micro-calcification ${ }^{10}$. Malignant nodules are differentiated from benign by their irregular and speculated margins and hypo-echogenicity ${ }^{11}$. According to the American College of Radiology, Thyroid Imaging Reporting and Data Systems (TIRADS) is a 5 point classification to determine the risk of cancer in thyroid nodules based on ultrasound characteristics. TIRADS 1 corresponds to a normal gland, TIRADS 2 to a benign nodule (both with $0 \%$ malignancy), and TIRADS 3 to a highly probable benign nodule ( $<5 \%$ malignancy), TIRADS 4 ( 5 to $80 \%$ malignancy) and 5 (>80\% malignancy)to suspicious nodule (TIRADS 4A, 4B and 4C corresponding to low, intermediate and moderate suspicion for malignancy ${ }^{12}$. Although B mode ultrasound is a helpful tool to diagnose thyroid nodules it has noticeably low accuracy to differentiate Benign from malignant ${ }^{13}$. The sensitivity and specificity of ultrasonography in the diagnosis of malignant nodules was $55 \%$ to $95 \%$ and $52 \%$ to $81 \%$ respectively ${ }^{14}$. Fine needle aspiration (FNA) is widely been used in differentiation of benign from malignant thyroid nodules having sensitivity and specificity ranging from $60-98 \%$ and $54-90 \%$ respectively ${ }^{15}$. Problems related with fine needle aspiration FNA are possibility of sampling, potential complications and analytical errors ${ }^{16}$. Elastography is a newly developed non- invasive technique which uses ultrasound and gives information about the stiffness of tissue by measuring the degree of distortion by applying an external force. Elastography use strain tissue deformation induced by compression and is determined by pre-compression and post-compression ultrasonic signals ${ }^{17}$. Shear wave Elastography (SWE) and real-time ultrasound Elastography (RTE) are the two types of Elastography ${ }^{18}$. According to the RTE mechanism softer part of tissue deform more easily than harder tissues under external pressure ${ }^{19}$. It estimates the hardness of thyroid lesions in association with adjacent tissues and assists in the differentiation of benign from malignant nodules and the stiffness of nodules depends upon there cellularity ${ }^{20}$. According to young modulus formula tissue elasticity can be reflected by the speed of shear wave propagation and real-time color-coded elastogram. Softer tissue appears in blue color while red color indicates relatively stiffer tissue ${ }^{21}$. A recent study shows a five pattern scoring scale for sonoelastography. A score of 1 or 2 was for benign and a score of 3 to 5 was for malignant thyroid nodules having sensitivity and specificity of $93.7 \%$ and $90 \%$ respectively and the positive predictive value was $71 \%$ and the negative predictive value was $98 \%{ }^{22}$. The aim of our study was to confirm the diagnostic accuracy of sonoelastography in the evaluation of benign and malignant thyroid nodules.

\section{$2 \quad$ Methods}

This study was performed in Radiology Department of Institute of Nuclear Medicine and Oncology Lahore (INMOL) Pakistan from 25 March 2019 to 23 August 2019 for duration of five months. Total 72 Patients of age between 18-80 years of either gender were included in our study after taking informed consent. Patients having one or more solid nodules in thyroid on conventional ultrasound examination were included in the study. Elastography was performed using Toshiba Aplio 500 to check the strain ratio of nodules. Elastography of nodules was confirmed with histopathological findings of nodules.

\section{$3 \quad$ Results}

A total 72 participants that fulfil our inclusion and exclusion criteria were included in our study. Age distribution shows that $43.1 \%(\mathrm{n}=31)$ were between $18-39$ years of age, $50.0 \%(\mathrm{n}=36)$ were between $40-59$ years of age and $6.9 \%(\mathrm{n}=5)$ were between $60-80$ years of age. (Table No.2). The mean age of participants was 42.11 years and the middle value of age was 42 years and the mode of ages was 32. (Table no.3a). Gender distribution of our study shows that $51.4 \%(\mathrm{n}=37)$ were male and $48.6 \%(\mathrm{n}=35)$ were female. (Table No.3). According to grey scale characteristics as described in ACR-TIRADS. The TIRADS-1 shows a normal thyroid gland (which was not included in our study), TIRADS-2 shows 25 benign lesions (34.7\%), TIRADS-3 shows 6 probably benign lesions or low risk malignant lesions (8.3\%), TIRADS-4 shows 7 lesions with increased risk of malignancy $(9.7 \%)$ and TIRADS-5 shows 34 Malignant lesions(47.2\%).(Table/Fig no.4). The participants which has only one nodule were $50 \%(\mathrm{n}=36)$, with 2 nodules were $26.4(\mathrm{n}=19)$ with 3 nodules were $6.9(\mathrm{n}=5)$ and with multiple nodules were 
$16.7 \%(n=12)$.(Table/Fig no.5). Out of 72 there were 25 benign and 6 probably benign those were included in benign category on the other hand 34 were malignant and 7 were increased risk of malignancy those were included in malignant category. (Fig no.4). Sonoelastographic strain ratio of nodules in participants according to the strain ratio of $55.6 \%$ nodules $(n=40)$ was more than 2.1 that shows the malignant feature of nodules and $44.4 \%$ nodules $(n=32)$ having strain ratio less than 2.1 it describes the benign nature of nodules. Here 2.1 is cut off value. (Table/Fig no.6) In $43.1 \%$ of participants $(n=31)$ having nodules were benign proved by the sonoelastography on the other hand $56.9 \%$ of participants $(n=41)$ having nodules were malignant assumed by Sonoelastography (Table/Fig no.7). Nature of nodules according to the results of histopathology showed $56.9 \%$ of participants $(n=41)$ having nodules were malignant assumed by histopathology. On the other side $43.1 \%$ of participants $(n=31)$ having nodules were benign as studied in histopathology of nodules. (Table/Fig no.8). The comparison of sonoelastography and histopathology in reference with nodules the results of histopathology and sonoelastographic assessment were same and support each other, in this study the sonoelastography of nodules confirmed with histopathology of nodules (Fig no.9). Sonoelastography strain ratio indicating benign and malignant features of nodules (Fig no. 10,11,12,13 \& 14).

\section{Age of the patients}

Table No. 2

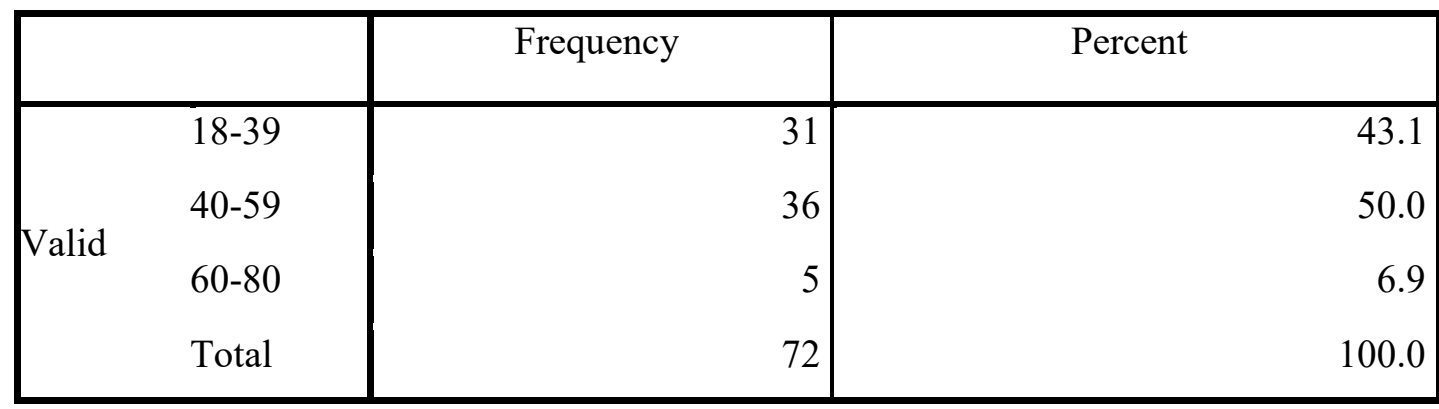

Table No. 2 shows that 31 participants belongs to the age group 18-39, out of 72 patients 36 patients were belongs to 40-59 age group and 5 patients were belong to age group 60-80.

\section{Statistics}

Table No. 3

\begin{tabular}{|l|r|}
\hline N & \\
Mean & 72 \\
Median & 42.11 \\
Mode & 42.00 \\
Std. Deviation & $32^{\mathrm{a}}$ \\
\hline
\end{tabular}

Table no. 3 shows the descriptive statistics of participant's age according to this table the mean age of participants was 42.11 . 


\section{Gender of patients}

Table No. 3a

\begin{tabular}{|l|r|r|}
\hline & Frequency & \multicolumn{2}{|c|}{ Percent } \\
\hline Male & 37 & 51.4 \\
Female & 35 & 48.6 \\
Total & 72 & 100.0 \\
\hline
\end{tabular}

Table No. 3a shows that out of 72 patients 37 patients were male and 35 were female.

\section{Grayscale Scoring System according to ACR TI-RADS}

Table No. 4

\begin{tabular}{|l|r|r|}
\hline & Frequency & \multicolumn{2}{|c|}{ Percent } \\
\hline 2(Benign lesions) & 25 & \\
3(Probably benign lesions or low & 6 & 8.7 \\
risk malignant lesions) & & \\
4(Lesions with increased risk of & 7 & 9.7 \\
malignancy) & & \\
5(Malignant lesions) & 34 & 47.2 \\
Total & 72 & 100.0 \\
\hline
\end{tabular}

Table No.4 Enumerates the grey scale characteristics as described in ACR-TIRADS lexicon with associated risk estimated for each feature. Nodules ACR-TIRADS category with its estimated risk and shows a representative case in this study which was categorized as ACR-TIRADS 1=Normal thyroid gland that were not present, $2=$ Benign lesions and benign lesions were 25 with percentage of $34.7 \%$, 3=Probably benign lesions or low risk malignant lesions these were $8.3 \%, 4=$ Lesions with increased risk of malignancy thy were $9.7 \%$ and $5=$ Malignant lesions those were $47.2 \%$.

\section{Fig No 4.}

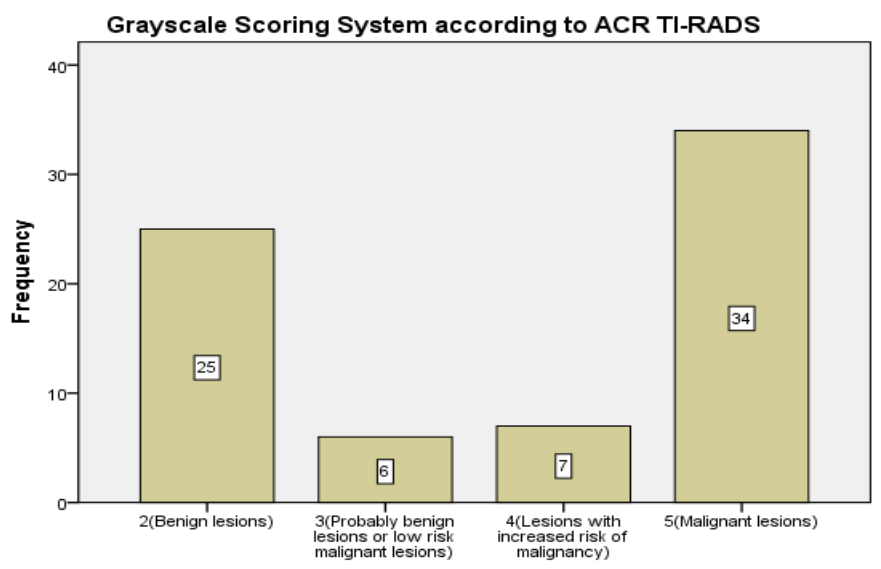

Grayscale Scoring System according to ACR TI-RADS 


\section{Number of Nodules}

Table No.5

\begin{tabular}{|l|r|r|}
\hline & Frequency & Percent \\
\hline $\mathbf{1}$ & 36 & 50.0 \\
$\mathbf{2}$ & 19 & 26.4 \\
$\mathbf{3}$ & 5 & 6.9 \\
Multiple & 12 & 16.7 \\
Total & 72 & 100.0 \\
\hline
\end{tabular}

Table No. 5 denoted the number of nodules in patients, the participants with only single nodule were $50 \%$ with 2,3 and multiple were $26.4 \%, 6.9 \%, 16.7 \%$ respectively.

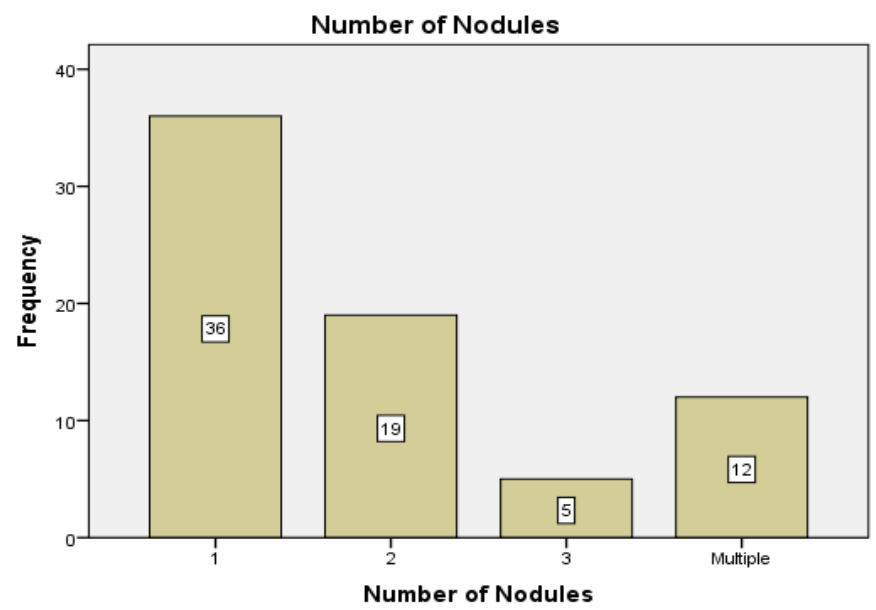

Fig No.5

Number of Nodules

\section{Sonoelastographic Strain Ratio}

Table No. 6

\begin{tabular}{|l|r|rr|}
\hline & \multicolumn{2}{|c|}{ Frequency } & \multicolumn{2}{|c|}{ Percent } \\
\hline $\begin{array}{l}\text { More than 2.1 } \\
\text { (Malignant) }\end{array}$ & 40 & 55.6 \\
$\begin{array}{l}\text { Less than 2.1 } \\
\text { (Benign) } \\
\text { Total }\end{array}$ & 32 & 44.4 \\
\hline
\end{tabular}

Table No.6 shows the frequency and percentages for sonoelastographic strain ratio of nodules in participants according to this table the strain ratio of $55.6 \%$ nodules was more than $2.1 \mathrm{~mm}$ that shows the malignant feature 
of nodules and $44.4 \%$ nodules having strain ratio less than $2.1 \mathrm{~mm}$ it describe the benign nature of nodules. Here 2.1 is cutoff value.

Fig No.6

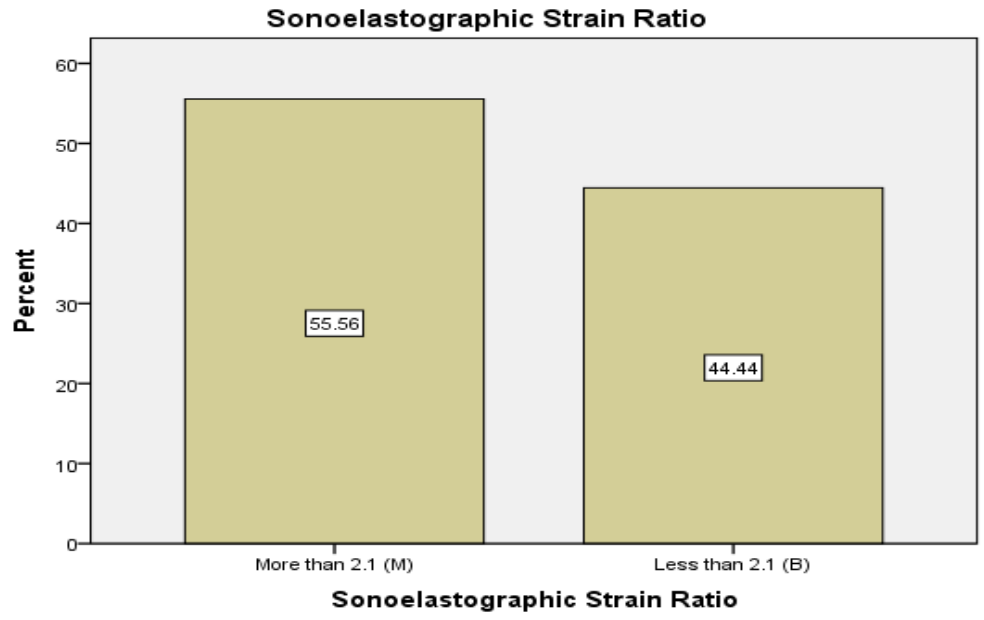

\section{Sonoelastography}

Table No.7

\begin{tabular}{|c|c|c|}
\hline & Frequency & Percent \\
\hline Benign & 31 & 43.1 \\
\hline Malignant & 41 & 56.9 \\
\hline Total & 72 & 100.0 \\
\hline
\end{tabular}

Following table elaborate nature of nodules according to sonoelastography, either nodule is malignant or benign. In this table $43.1 \%$ of participants having nodules were benign proved by the sonoelastography on the other hand $56.9 \%$ of participants having nodules were malignant assumed by sonoelastography.

\section{Fig No.7}

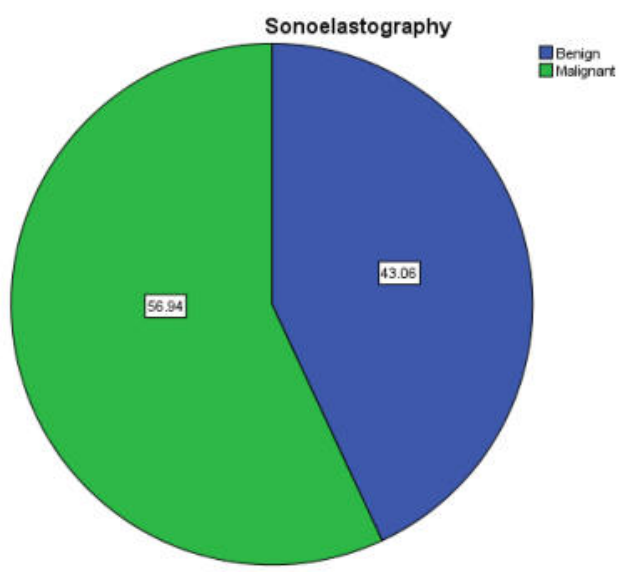




\section{Histopathology}

Table No.8

\begin{tabular}{|l|r|rr|}
\hline & Frequency & \multicolumn{2}{|c|}{ Percent } \\
\hline Benign & 31 & 43.1 \\
Malignant & 41 & 56.9 \\
Total & & 72 & 100.0 \\
\hline
\end{tabular}

This table enumerate nature of nodules according to histopathology, after histopathology of nodules the results showed $56.9 \%$ of participants having nodules were malignant assumed by histopathology. On the other side $43.1 \%$ of participants having nodules were benign as studied in histopathology of nodules.

\section{Fig No.8}

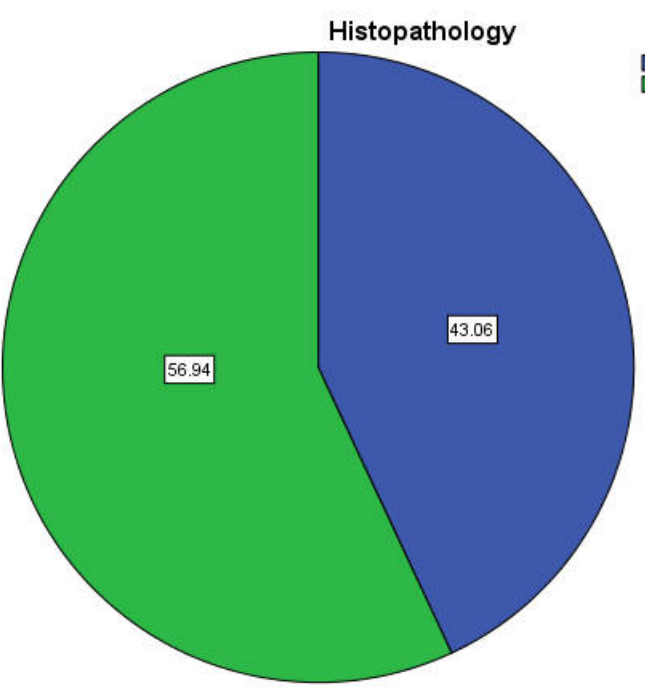

Fig No.8 Following fig represent the results of histopathology of nodules in patients 


\section{Fig No.9}

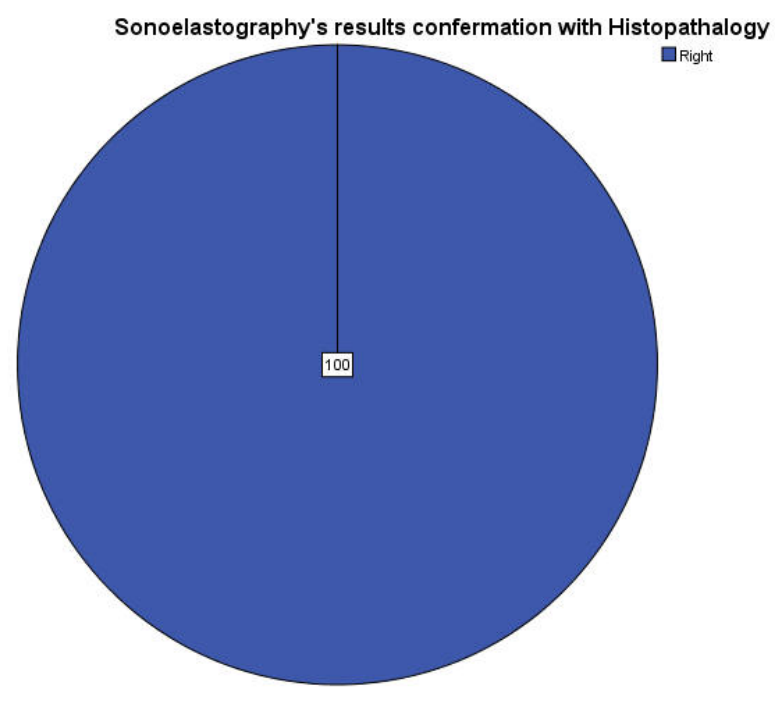

Fig No.9 Following figure shows the comparison of sonoelastography and histopathology in reference with nodules.

\section{Elastography Scans}

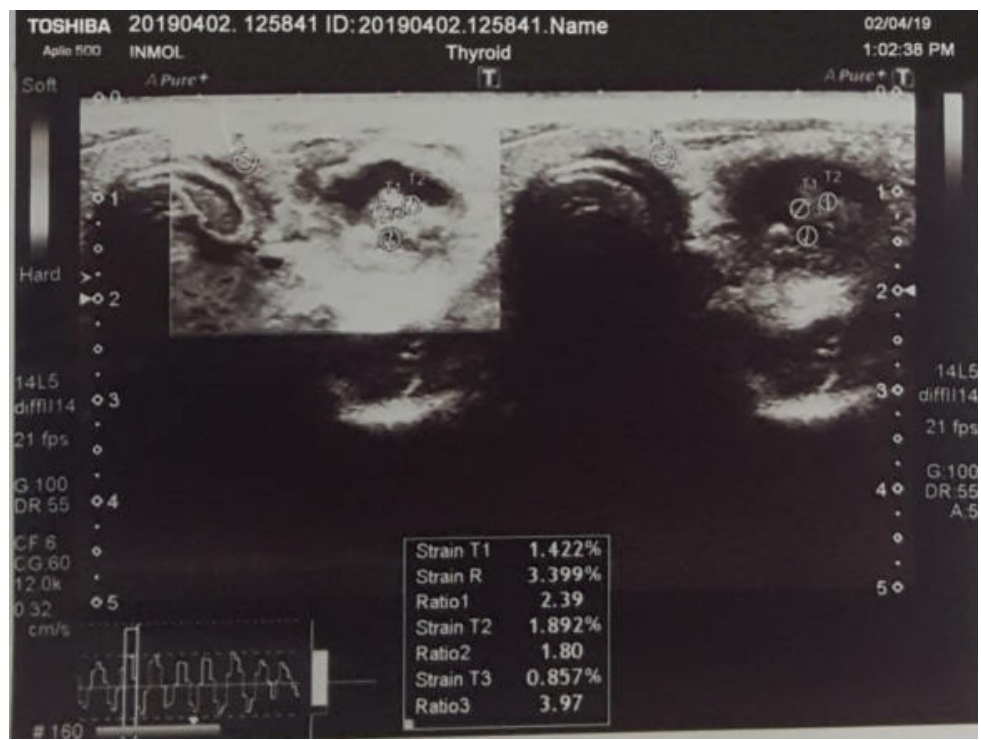

Fig No.10 shows the sonoelastograpgy strain ratio of 2.39 which is suspicious for being malignant. 


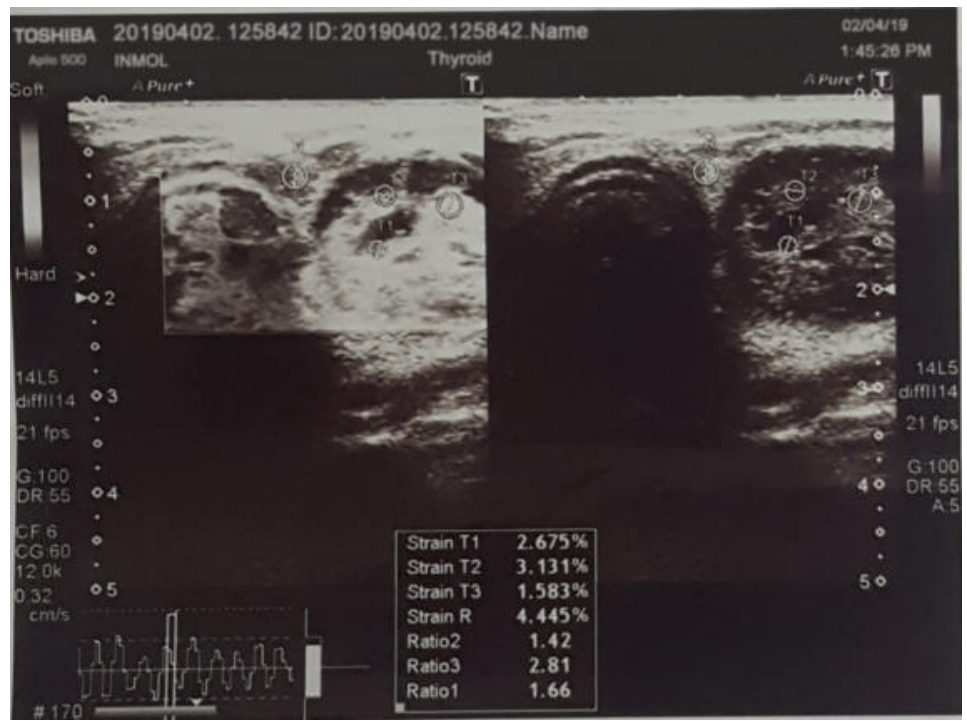

Fig No.11 shows the sonoelastograpgy strain ratio of 2.81 which is suspicious for being malignancy.

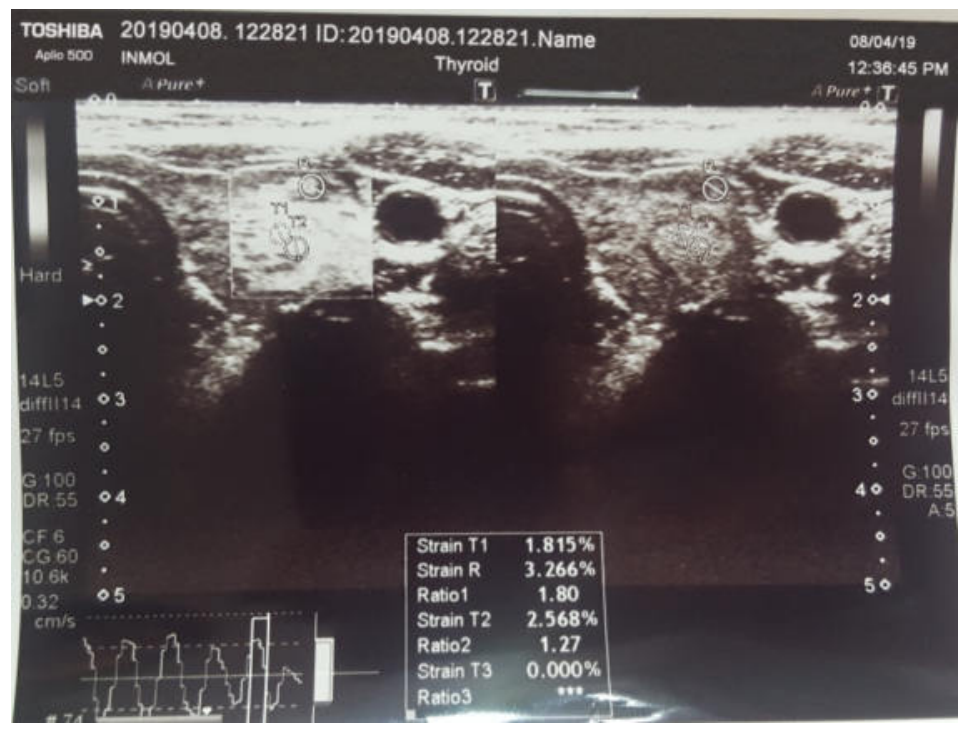

Fig No.12 shows the sonoelastograpgy strain ratio of 1.27 which is benign feature. 


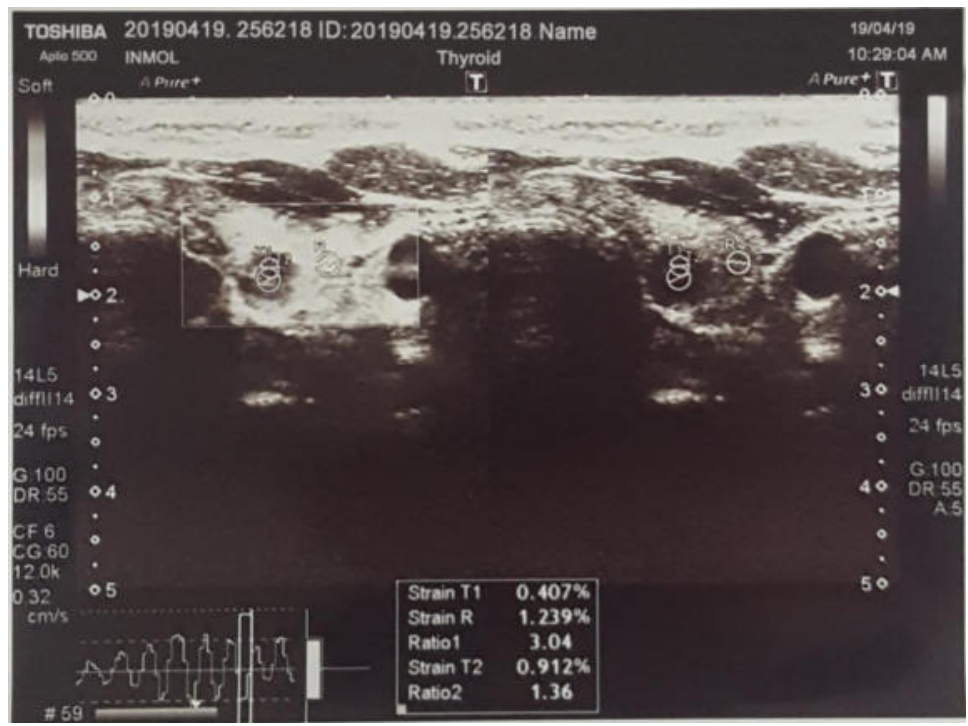

Fig No.13 shows the sonoelastograpgy strain ratio of 3.04 which is malignant feature.

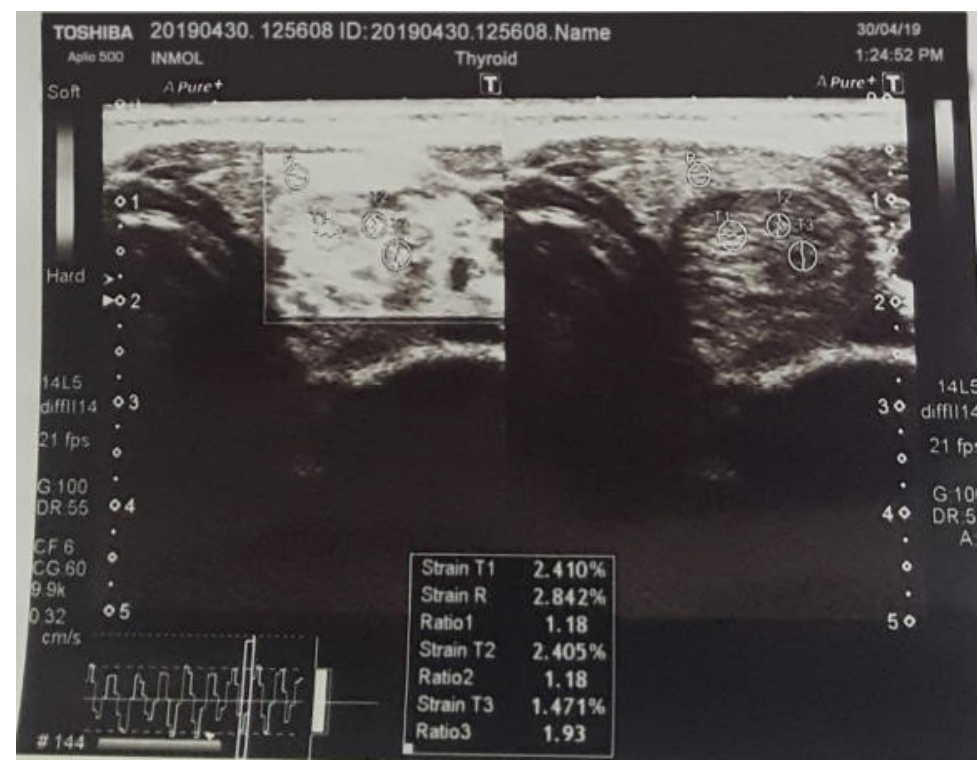

Fig No.14 shows the sonoelastograpgy strain ratio of 1.93 which is likely benign. 


\section{$4 \quad$ Discussion}

Sonoelastography is a fresh technology with advanced dynamic technique that assesses the differential tissue characteristics using a tissue rigidity/elasticity ratio. It assesses the point of alteration of a tissue with the help of controlled external force, measures changes between different tissue elasticity. Malignant lesions are mostly linked with changes in the mechanical proprieties of a tissue, and Sonoelastography addresses this characteristic. A similar study conducted and findings were found as age group of study population ranged from 20-75years. Most of the patients in this age group were between 35-50 years (55\%). Fifty patients were evaluated in the present study. Out of the 50 patients, 40 were females $(80 \%)$ and 10 were males $(20 \%)^{23}$. Grey scale characteristics as described in ACR-TIRADS lexicon with associated risk estimated for each feature. Nodules ACR-TIRADS category with its estimated risk and shows a representative case in this study which was categorized as ACRTIRADS $1=$ Normal thyroid gland that were not present, 2=Benign lesions and benign lesions were 25 with percentage of $34.7 \%, 3=$ Probably benign lesions or low risk malignant lesions these were $8.3 \%$, 4=Lesions with increased risk of malignancy thy were $9.7 \%$ and $5=$ Malignant lesions those were $47.2 \%$.

Sonoelastography has newly been practical in the diagnostic method to nodular thyroid disease. In our study age wise distribution of samples revealed that 31 participants belongs to the age group 18-39, out of 72 patients 36 patients were belongs to 40-59 age group and 5 patients were belong to age group 60-80. Descriptive statistics of participant's age reveal that mean age of participants was 42.11 year and the middle value of age was 42 year and the mode of ages was 32 in this table alpha denoted the multiple modes existence in data and 32 is smallest value. In percentage, $7 \%$ patients were to age group $60-80$, out of total $50 \%$ were belong to age group $40-59$ and $43 \%$ were from age group 18-39. Gender wise distribution shows out of 72 patients 37 patients were male and 35 were female; out 100 percent $49 \%$ were female and $51 \%$ were male participants.

According to the study done by B. Raghavan et al. the correlation of the benign lesions were 99.2\% in TIRADS 2 and 100\% in TIRADS 3 category, the correlation of the lesion being malignant was $100 \%$ in TIRADS 4 category and $91 \%$ in TIRADS 5. But in our study we found that out of 72 there were 25 benign 6 probably benign those were included in benign category on the other hand 34 were malignant and 7 were increased risk of malignancy those were included in malignant category ${ }^{24}$. In present study sonoelastographic strain ratio of nodules in participants were as following; strain ratio of 55.6\% nodules was more than $2.1 \mathrm{~mm}$ that shows the malignant feature of nodules and $44.4 \%$ nodules having strain ratio less than $2.1 \mathrm{~mm}$ it describes the benign nature of nodules. Here 2.1 is cutoff value.

Sonoelastography and histopathology in reference with nodules according to our results of histopathology and sonoelastographic assessment were same and support each other, in this study the results of sonoelastography confirmed right with histopathology. So according to over study Sonoelastography is an ideal imaging technique for characterizing malignant and benign thyroid nodules.

\section{Conclusion}

Sonoelastography is non-invasive and cost-effective imaging technique to diagnose thyroid nodules either benign or malignant.

\section{Recommendations}

Based on the findings of this study recommendations are following:

- Sonoelastography is reliable way to find out the characteristics of nodules either benign or malignant.

- In response of this study further studies should be done with in details by comparing sonoelastography with other diagnostic methods.

A more comprehensive study needs to be examined with more generalizability by increasing sample size and study settings.

\section{$7 \quad$ Limitations:}

Sample size was small so the generalization of the findings is limited.

Study was conducted only in one Hospital so the generalization of the finding is limited. 


\section{Acknowledgement:}

First and foremost, we would like to thank Allah Almighty for giving us the strength, knowledge and ability to undertake this research study, to persevere and complete it satisfactorily. Without His blessings, this achievement would not have been possible.

In our journey towards this degree, we have found a teacher, a role model and a pillar of support, Prof. Dr. Syed Amir Gillani, Dean, FAHS. A special thanks to him for providing his heartfelt support and guidance at all times. We wish to express our sincere thanks to Prof. Dr. Sajid Shaheen Malik, Head of Department, UIRSMIT, for providing us with all the necessary facilities for the research.

We take pride in acknowledging Prof. Dr. Sajid Shaheen Malik, our supervisor who has given us invaluable guidance and suggestions in our quest for knowledge, ensuring that we stay on course and do not deviate from the core of our research. Without his able guidance, this thesis would not have been possible and we shall eternally be grateful to him.

We have great pleasure in acknowledging our gratitude to Ms. Mehreen Fatima, our biostatician and Syed Yousaf Gillani for sparing their valuable time whenever we approached them and showing us the way ahead by being so helpful and cooperative.

It would be inappropriate if we do not mention our friends, who have, in their own ways, assisted us as per their abilities, in whatever manner possible.

Our acknowledgement would be incomplete without thanking the biggest source of our strength, our families. We thank them for putting up with us in difficult times and for goading us on to follow our dream of getting this degree. This would not have been possible without their unwavering love and support given to us at all times.

\section{References:}

1. Zou S, Wu F, Guo C, Song J, Huang C, Zhu Z, et al. Iodine nutrition and the prevalence of thyroid disease after salt iodization: a cross-sectional survey in Shanghai, a coastal area in China. PLoS One. 2012;7(7):e40718.

2. Cooper DS, Doherty GM, Haugen BR, Kloos RT, Lee SL, Mandel SJ, et al. Revised American Thyroid Association management guidelines for patients with thyroid nodules and differentiated thyroid cancer: the American Thyroid Association (ATA) guidelines taskforce on thyroid nodules and differentiated thyroid cancer. Thyroid. 2009;19(11):1167-214.

3. Alam T, Khattak YJ, Beg M, Raouf A, Azeemuddin M, Khan AA. Diagnostic accuracy of ultrasonography in differentiating benign and malignant thyroid nodules using fine needle aspiration cytology as the reference standard. Asian Pac J Cancer Prev. 2014;15(22):10039-43.

4. Rajini T, Ramachandran A, Savalgi GB, Venkata SP, Mokhasi V. Variations in the anatomy of the thyroid gland: clinical implications of a cadaver study. Anatomical science international. 2012;87(1):45-9.

5. Mandel SJ. A 64-year-old woman with a thyroid nodule. Jama. 2004;292(21):2632-42.

6. Lin J-D, Chao T-C, Huang B-Y, Chen S-T, Chang H-Y, Hsueh C. Thyroid cancer in the thyroid nodules evaluated by ultrasonography and fine-needle aspiration cytology. Thyroid. 2005;15(7):708-17.

7. Reiners C, Wegscheider K, Schicha H, Theissen P, Vaupel R, Wrbitzky R, et al. Prevalence of thyroid disorders in the working population of Germany: ultrasonography screening in 96,278 unselected employees. Ibid. 2004;14(11):926-32.

8. Khan MA, Khan KH, Shah SA, Mir KA, Khattak M, Shahzad MF. Risk factors associated with thyroid carcinoma in North Pakistan. Asian Pac J Cancer Prev. 2016;17(1):377-80.

9. Islam N. Thyroid Carcinoma. JPMA-Journal of the Pakistan Medical Association. 2011;61(10):949.

10. Krikorian A, Kikano G. Thyroid nodules: when is an aggressive evaluation warranted? Relatively few nodules require therapeutic intervention. A prudent selection of laboratory and imaging studies using this algorithm will yield a reliable assessment. Journal of Family Practice. 2012;61(4):205-9.

11. Cappelli C, Castellano M, Pirola I, Gandossi E, De Martino E, Cumetti D, et al. Thyroid nodule shape suggests malignancy. European journal of endocrinology. 2006;155(1):27-31.

12. Guilherme F DRN, Rodrigo G Garcia. Fine needle aspiration biopsy of thyroid nodule smaller than $1.0 \mathrm{~cm}$ : accuracy of TIRADS classification system in more than 1000 nodules. 2017;91(1083). 
13. Xing P, Wu L, Zhang C, Li S, Liu C, Wu C. Differentiation of benign from malignant thyroid lesions: calculation of the strain ratio on thyroid sonoelastography. Journal of ultrasound in medicine. 2011;30(5):663-9.

14. Tamsel S, Demirpolat G, Erdogan M, Nart D, Karadeniz M, Uluer H, et al. Power Doppler US patterns of vascularity and spectral Doppler US parameters in predicting malignancy in thyroid nodules. Clinical radiology. 2007;62(3):245-51.

15. Peng Y, Wang HH. A meta-analysis of comparing fine-needle aspiration and frozen section for evaluating thyroid nodules. Diagnostic cytopathology. 2008;36(12):916-20.

16. Asteria C, Giovanardi A, Pizzocaro A, Cozzaglio L, Morabito A, Somalvico F, et al. US-elastography in the differential diagnosis of benign and malignant thyroid nodules. Thyroid. 2008;18(5):523-31.

17. Iannuccilli JD, Cronan JJ, Monchik JM. Risk for malignancy of thyroid nodules as assessed by sonographic criteria. Journal of Ultrasound in Medicine. 2004;23(11):1455-64.

18. Tian W, Hao S, Gao B, Jiang Y, Zhang S, Guo L, et al. Comparison of diagnostic accuracy of real-time elastography and shear wave elastography in differentiation malignant from benign thyroid nodules. Medicine. 2015;94(52).

19. Tian W, Hao S, Gao B, Jiang Y, Zhang X, Zhang S, et al. Comparing the diagnostic accuracy of RTE and SWE in differentiating malignant thyroid nodules from benign ones: a meta-analysis. Cellular Physiology and Biochemistry. 2016;39(6):2451-63.

20. Hoang JK, Lee WK, Lee M, Johnson D, Farrell S. US Features of thyroid malignancy: pearls and pitfalls. Radiographics. 2007;27(3):847-60.

21. Kwak JY, Kim E-K. Ultrasound elastography for thyroid nodules: recent advances. Ultrasonography. 2014;33(2):75.

22. Eltyib HEH, Awad IA, Elsayed NM, Jastaniah SD. Real time ultrasound elastography for the differentiation of benign and malignant thyroid nodules. Open Journal of Medical Imaging. 2014;4(1):38.

23. Dr. Nagaraj Murthy DRR, Dr. Geetha .M .J. Role of Elastography in Ultrasound Evaluation of Thyroid Nodules. International Journal of Science and Research (IJSR). 2017;6(5).

24. Popli, M. B., et al. (2012). "Utility of gray-scale ultrasound to differentiate benign from malignant thyroid nodules." The Indian journal of radiology \& imaging 22(1): 63 